\title{
Diagnosis of mitral insufficiency using impedance cardiography technique ICG
}

\author{
Souhir Chabchoub ${ }^{1,3}$, Sofienne Mansouri ${ }^{1}$ and Ridha B. Salah ${ }^{2}$ \\ 1. University of Tunis El-Manar, ISTMT, Laboratory of Biophysics and Medical Technologies, Tunis, Tunisia \\ 2. Salman Bin Abdulaziz University \& College of Applied Medical Sciences, Saudi Arabia \\ 3. E-mail any correspondence to: chabchoub_souhir@yahoo.fr
}

\begin{abstract}
Impedance cardiography (ICG) is a non-invasive tool for assessing the hemodynamic parameters. It has been used for diagnosing several cardiovascular diseases, such as heart failure, cardiomyopathy, and valvular diseases. Particularly, the valvular heart disease is characterized by the damage in one of the four heart valves: the mitral, aortic, tricuspid or pulmonary valves. The mitral valve insufficiency and the aortic valve stenos are the most frequent valve diseases in the world. In this paper, we propose to diagnosis the mitral valve insufficiency using the impedance cardiography technique. The study group consisted of 40 subjects (20 control subjects and 20 patients with mitral insufficiency). A parameter "I" is calculated from the impedance cardiogram waveform and it is used to differentiate control subjects from patients with mitral insufficiency. The parameter "I" was related significantly to the abnormalities of the impedance cardiogram waveform. For patients with mitral insufficiency, "I" was higher than for the healthy subjects with a difference ratio of $89 \%$ $(\mathrm{p}<0.001)$. To improve the diagnosis, we determined the stroke volume, cardiac output, and other hemodynamic parameters for the two groups of subjects. Finally, we concluded that we could identify, easily, patients with mitral insufficiency based on the abnormalities of the impedance cardiogram tracings and a characteristic parameter "I".
\end{abstract}

Keywords: Impedance Cardiography, mitral insufficiency, hemodynamic parameters, parameter "I"

\section{Introduction}

Impedance cardiography (ICG) is a simple, non-invasive, and cost effective technique for assessing stroke volume (SV), cardiac output (CO) and others hemodynamic parameters [1]. In order to establish its validity, ICG has been widely compared to several methods which measure stroke volume and cardiac output [3], such as echocardiography $[4,5]$, thermodilution [6,7], and the Fick method [8]. Impedance cardiography has been used for many clinical purposes. It has been used for diagnosing several cardiovascular diseases such as heart failure [9-10] and myocardial infarction [11]. Moreover, it has been used to detect ischemia [12]. Furthermore, it may be useful to examine the effect of different diseases of the autonomic nervous system like the Parkinson's disease [13, 14], for monitoring pregnant women $[15,16]$, for diagnosis and treatment of patients with hypertension $[17,18]$. Likewise, it has been used to monitor surgical operations $[19,20]$ and dialyzed patients $[21,22]$.
Mitral Insufficiency (MI), called also mitral regurgitation, is defined as systolic retrograde flow from the left ventricle into the left atrium [23]. MI is the most-frequent valvular heart disease in the world and it is constituted as the second most prevalent valve disease after aortic valve stenosis. The major complication of MI is heart failure, pulmonary hypertension, atrial fibrillation, and death [24]. There are several diagnostic tools in assessing Mitral Insufficiency such as the chest X-ray, the echocardiography, and catheterization. The most interesting diagnostic technique that can provide important information about MI is echocardiography, especially the Doppler echocardiography [25-27]. However, this technique is expensive and often not necessary for making a diagnosis [28]. Otherwise, there are few studies, which discussed the ability of the impedance cardiography method to diagnose Mitral Insufficiency. Karnegis et al. have calculated an index from the ICG tracings, which may be useful in identifying patients with mitral regurgitation [29]. Schieken et al. have determined a mitral regurgitation fraction that is the ratio of the areas of the first systolic and diastolic waves [30]. Viscor et al. have discussed the ability of impedance cardiography to measure the change of stroke volume during a Mueller maneuver in patients with mitral regurgitation [31].

Some literature reviews have affirmed that the waves A and $\mathrm{O}$ in the ICG waveform were considered as a marker of the mitral insufficiency pathology. Lababidi et al., Takada et al. and other groups have demonstrated that the amplitude of the wave A is highly correlated to the left atrial ejection fraction [39]. On the other hand, the maximum of the wave $\mathrm{O}$ coincides with the opening of the mitral valve in patients with mitral stenosis [40] and the increase of $\mathrm{O}$-wave size has been marked in patients with mitral valve pathology [41]. Thus, the amplitude of the A and $\mathrm{O}$ waves can facilitate the diagnosis of the mitral valve diseases.

The main aim of our study is to compare the change of impedance cardiogram waveforms in control subjects and patients with mitral insufficiency. Firstly, we propose to discuss the amplitudes of A-wave and O-wave. Then, we suggest calculating a parameter "I" that can facilitate the diagnosis of mitral valve diseases. Furthermore, we determine hemodynamic parameters for improving the comparison between the ICG tracings and for evaluating the importance of the proposed parameter "I". 


\section{Materials and methods}

\section{Subjects}

A total of forty subjects participated in this study; twenty control subjects (10 males and 10 females) having an average age of $30 \pm 10$ years (ranging from 21 to 49 years), and twenty patients with mitral insufficiency (10 males and 10 females) having an average age of $44 \pm 8$ years (ranging from 24 to 50 years). We selected for this work patients with isolated mitral insufficiency, the patients who had additional diseases were excluded.

\section{Measurements}

The ICG recording method used in this study consists of applying a low level current and high frequency (1 mA, 30 $\mathrm{kHz}$ ), through two electrodes placed in front of and above the leading edge of the heart, respectively. Two other electrodes are placed on the chest of the patient at the level of the aorta, 2 or $3 \mathrm{~cm}$ apart permitting registration of impedance variation of the explored thoracic region. During the signal recording, the patient must lie supine, relaxed and in expiratory apnea for a period of 10 seconds [32]. Figure 1 shows the electrode configuration for the measurement of the ICG signal.

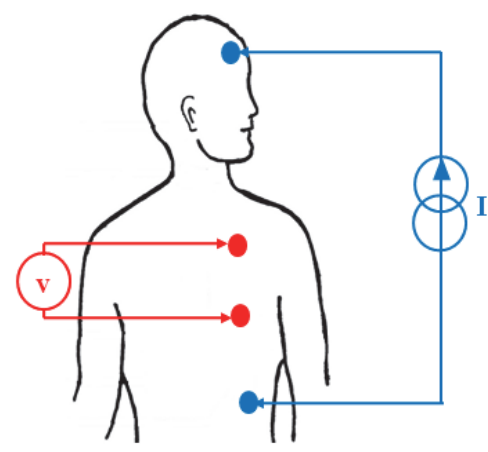

Fig.1: Electrodes configuration for the measurement of the ICG signal.

\section{ICG signal}

The typical ICG waveform and its characteristic points are shown in Figure 2. A, B, C, X and $\mathrm{O}$ are the main characteristic points of the ICG trace. These points are related to distinct physiological events in the cardiac cycle. The description of those points is presented in Table 1 .

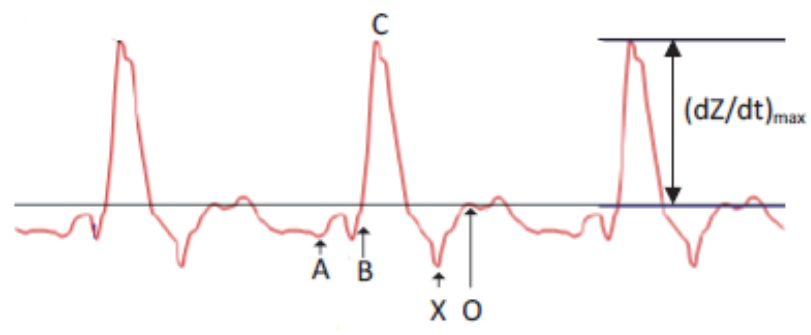

Fig.2: A typical ICG signal.
Table 1. Characteristic points on the ICG signal

\begin{tabular}{|c|c|}
\hline $\begin{array}{l}\text { Characteristic } \\
\text { points }\end{array}$ & Description \\
\hline A & $\begin{array}{l}\text { Is the beginning of electromechanical } \\
\text { systole. It is associated with the atrial } \\
\text { contraction. }\end{array}$ \\
\hline B & $\begin{array}{l}\text { Appears simultaneously with the } \\
\text { opening of the aortic valve. The precise } \\
\text { identification of a B point is important } \\
\text { for accurate calculation of stroke } \\
\text { volume and cardiac output [33]. It } \\
\text { denotes the beginning of the ejection } \\
\text { time. It has been reported that the } \\
\text { marker of this point is not always } \\
\text { apparent [34] and it may occur at any } \\
\text { point on the ascending portion of the } \\
\text { signal before the (dZ/dt) max }[35,36] \text {. }\end{array}$ \\
\hline $\mathrm{C}$ & $\begin{array}{l}\text { Is taken at the peak of the ICG signal } \\
\text { and it corresponds to the ventricular } \\
\text { contraction. The amplitude of this point } \\
\text { is used to calculate the stroke volume } \\
\text { and cardiac output. }\end{array}$ \\
\hline $\mathrm{X}$ & $\begin{array}{l}\text { Is the lowest point after the peak and it } \\
\text { is associated with the closure of the } \\
\text { aortic valve. It indicates the end of the } \\
\text { systole [37]. }\end{array}$ \\
\hline $\mathrm{O}$ & $\begin{array}{l}\text { Is associated with changing of the } \\
\text { volume during the diastolic phase of } \\
\text { the cycle and the maximal opening of } \\
\text { the mitral valve [37]. }\end{array}$ \\
\hline
\end{tabular}

\section{Hemodynamic parameters}

The main hemodynamic parameters that can be estimated from the ICG signal are the Heart Rate (HR), the Ejection Time interval (LVET), the Stroke Volume (SV) and the Cardiac Output (CO). The LVET, described as Left Ventricular Ejection Time, is the time interval measured from the B point to the $\mathrm{X}$ point; this parameter is used to estimate stroke volume and cardiac output. Moreover, the stoke volume is the volume of blood pumped by the left ventricle during one contraction cycle. Furthermore, the cardiac output is the volume of blood ejected by the heart into the systemic circulation during $1 \mathrm{~min}$ [33].

In order to compute the stroke volume, several equations have been proposed by; Kubicek [38], Stramek, Stramek-Bernstein [2], etc. In this work, the StramekBernstein formula is used:

$$
\mathrm{SV}_{\mathrm{S}-\mathrm{B}}=\delta \frac{\mathrm{L}^{3}}{4.25 \times \mathrm{Z}_{0}} \operatorname{LVET}\left(\frac{\mathrm{dz}}{\mathrm{dt}}\right)_{\max }(\mathrm{ml})
$$

Where $\delta$ is the weight correction for blood volume, L is the measured thoracic length between voltage sensing electrodes $(\mathrm{cm}), Z_{0}$ is the basic impedance $(\Omega),\left(\frac{d Z}{d t}\right)_{\text {max }}$ is 
the maximum value of the ICG waveform $(\Omega / \mathrm{s})$, and LVET is the ejection time (s).

The cardiac output (CO) is related to stroke volume as follows:

$$
\mathrm{CO}_{\mathrm{S}-\mathrm{B}}=\mathrm{SV}_{\mathrm{S}-\mathrm{B}} \times \mathrm{HR} \quad(1 / \mathrm{min})
$$

Where HR is the heart rate (bpm).
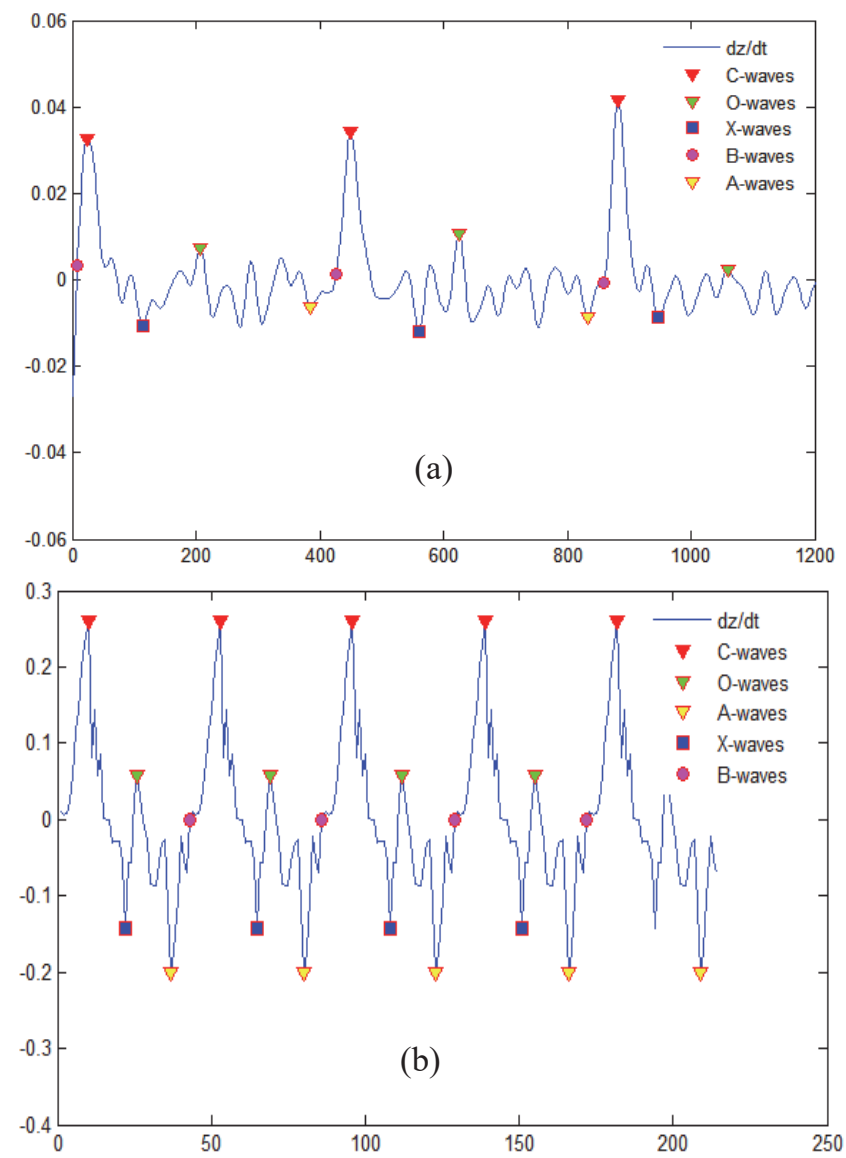

Fig.3: Impedance Cardiography traces recorded in (a) a control subject and (b) a patient with mitral insufficiency and the detection of the characteristic points (C-waves: red triangles, Owaves: green triangles, $\mathrm{A}$-waves: yellow triangles, $\mathrm{X}$-waves: blue squares, B-waves: pink circles).

\section{Measurements}

Throughout this study, a comparison is performed between control subjects and patients with mitral insufficiency. As a first step, the main characteristic points of the ICG waveform are detected by using Matlab software. Figure 3 presents two ICG traces recorded from a control subject (top strip) and from a patient with mitral insufficiency (bottom strip). Based in this figure and by visual inspection, we noticed that the shape of the ICG waveform in a patient with mitral insufficiency is different relative to the control subjects. Mainly, there is a distinct increase in the waves A and $\mathrm{O}$ for patients with MI. In order to quantify the increase of $\mathrm{A}$ and $\mathrm{O}$ waves, the amplitudes of these waves are computed. Thereafter, a helpful parameter "I" is introduced that can distinguish between control subjects and patients with MI. This parameter is equal to the difference between the amplitudes of wave $\mathrm{O}$ and wave $\mathrm{A}(\mathrm{I}=\mathrm{O}-\mathrm{A})$. In the second step, the main hemodynamic parameters are computed and compared for the two groups of subjects.

\section{Statistical Analysis}

Data were expressed as mean \pm standard deviation (SD). Student's t-test was used to evaluate the difference in parameters between two groups of subjects (control subjects and patients with MI). The Receiver Operating Characteristic (ROC) curve was utilized to evaluate the ability of the O-wave amplitude, the A-wave amplitude, and the diagnosis parameter "I" for discriminating between control subjects and patients with MI. The ROC curve was generated using the MedCalc software, version 16.8. The optimum cut-off, sensitivity (Se), specificity ( $\mathrm{Sp}$ ), negative predictive values (NPV), positive predictive values (PPV), and the area under the ROC curve (AUC) were calculated and compared. A $\mathrm{p}$-value of $\mathrm{p}<0.05$ was considered statistically significant.

\section{Results}

The A and O wave amplitudes, and the parameter "I" for control subjects and patients with MI are illustrated in Table 2. Student's t-test showed that there were highly significant differences between control subjects and patients with mitral insufficiency in $\mathrm{O}$ wave amplitude, $\mathrm{A}$ wave amplitude, and the characteristic parameter "I" $(\mathrm{p}<0.001)$.

The O, A, and "I" mean values significantly increased, by a percentage of $77 \%, 92 \%$, and $89 \%$, respectively, in patients with MI compared to those in the control group (Figure 4). In particular, the diagnosis parameter "I" significantly increased in patients with MI compared to control subjects $(2.7 \pm 1.5 \mathrm{Ohm} / \mathrm{s}$ vs $25.3 \pm 0.4 \mathrm{Ohm} / \mathrm{s})$.

Table 2. ICG wave amplitudes for control subjects and patients with mitral insufficiency (mean \pm SD)

\begin{tabular}{|c|c|c|c|}
\hline \multicolumn{1}{|c|}{ ICG waves } & $\begin{array}{c}\text { Control } \\
\text { subjects }\end{array}$ & $\begin{array}{c}\text { Patients } \\
\text { with MI }\end{array}$ & t-values \\
\hline $\mathrm{O}(\mathrm{Ohm} / \mathrm{s}) \cdot 10^{-3}$ & $1.2 \pm 1.2$ & $5.3 \pm 0.4$ & $14.4^{*}$ \\
\hline $\mathrm{A}(\mathrm{Ohm} / \mathrm{s}) \cdot 10^{-3}$ & $-1.5 \pm 0.2$ & $-20 \pm 0.004$ & $403.5^{*}$ \\
\hline $\mathrm{I}(\mathrm{Ohm} / \mathrm{s}) \cdot 10^{-3}$ & $2.7 \pm 1.5$ & $25.3 \pm 0.4$ & $63.24^{*}$ \\
\hline
\end{tabular}

Note: O: amplitude of $\mathrm{O}$ wave; A: amplitude of A wave; I: difference between the amplitudes of $\mathrm{O}$ and A waves; ${ }^{*} \mathrm{p}<0.001$ : the differences are highly significant. 

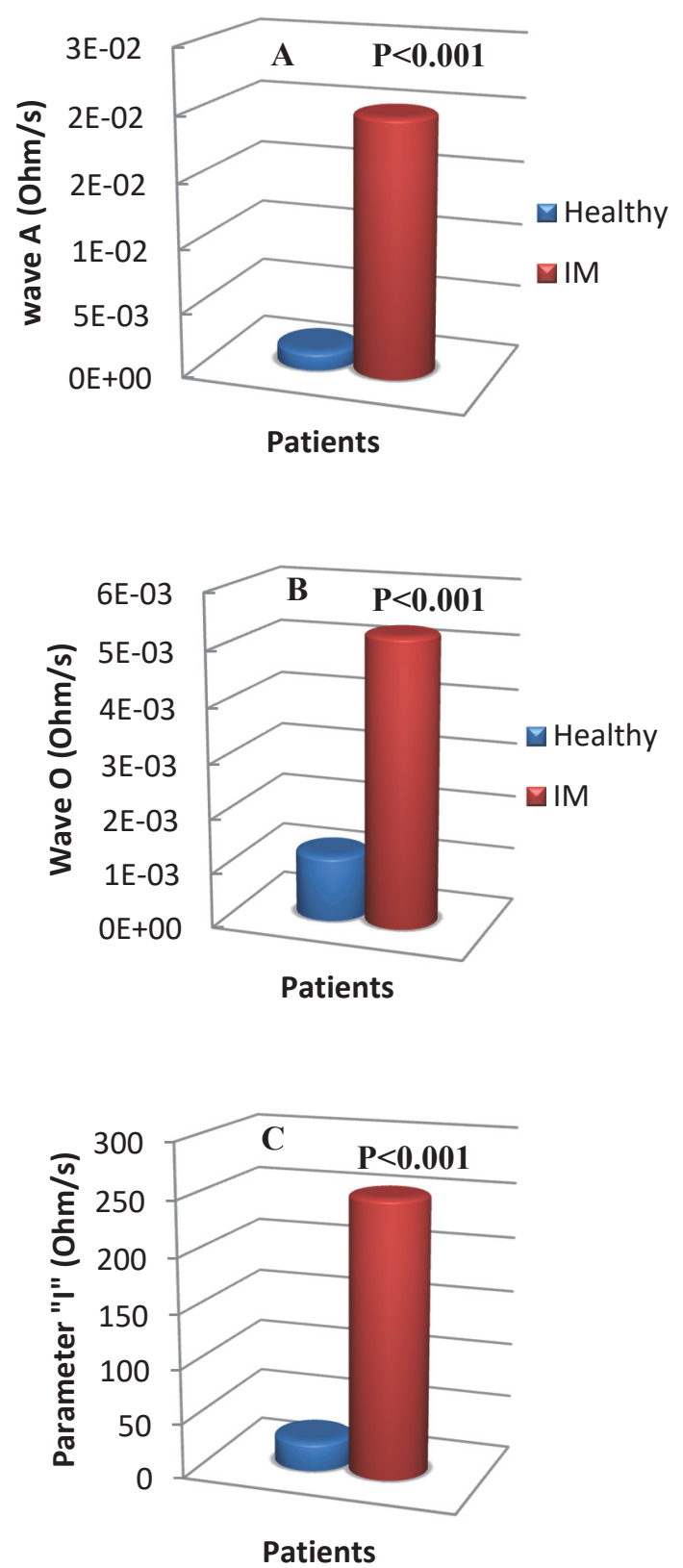

Fig.4: Difference between patients with mitral insufficiency (red) and control subjects (blue): (A) Histogram of the A-wave amplitude, (B) Histogram of the O-wave amplitude, (C) Histogram of the determined parameter "I".

The ROC curve analysis results of the O-wave amplitude, A-wave amplitude, and the parameter "I" are shown in Table 3. For the O-wave, an optimum cut-off $>3.64 \mathrm{Ohm} / \mathrm{s}$ had a sensitivity of $70 \%$, a specificity of $100 \%$, a positive predictive value of $100 \%$, and a negative predictive value of $100 \%$. The wave A (optimum cut-off $\leq-20 \mathrm{Ohm} / \mathrm{s}$ ) and the parameter "I" (optimum cut-off $>5.44 \mathrm{Ohm} / \mathrm{s}$ ), have the same statistical results (sensitivity, specificity positive predictive value, and negative predictive value of $100 \%$ ). The AUC of the ROC curve for the O-wave amplitude, Awave amplitude, and "I" were $0.96,1$ and 1 , respectively (p $<0.0001$ ) (Figure 5).
Table 3. ROC curve analysis of $\mathrm{O}$-wave amplitude, A-wave amplitude, and the characteristic parameter "I"

\begin{tabular}{|c|c|c|c|c|c|c|c|}
\hline $\begin{array}{c}\text { Amplitude } \\
(\mathrm{Ohm} / \mathrm{s})\end{array}$ & AUC & $P$ & $\begin{array}{c}\text { Optimum } \\
\text { cut-off }\end{array}$ & $\begin{array}{c}\text { Se } \\
(\%)\end{array}$ & $\begin{array}{c}\text { Sp } \\
(\%)\end{array}$ & $\begin{array}{c}\text { PPV } \\
(\%)\end{array}$ & $\begin{array}{c}\text { NPV } \\
(\%)\end{array}$ \\
\hline $\mathrm{O}$ & 0.96 & $<0.0001$ & $>3.64$ & 70 & 100 & 100 & 96.8 \\
\hline $\mathrm{A}$ & 1 & $<0.0001$ & $\leq-20$ & 100 & 100 & 100 & 100 \\
\hline $\mathrm{I}$ & 1 & $<0.0001$ & $>5.44$ & 100 & 100 & 100 & 100 \\
\hline
\end{tabular}

Note: AUC: area under the ROC curve; Se: sensitivity; Sp: specificity; PPV: positive predictive value; NPV: negative predictive value.

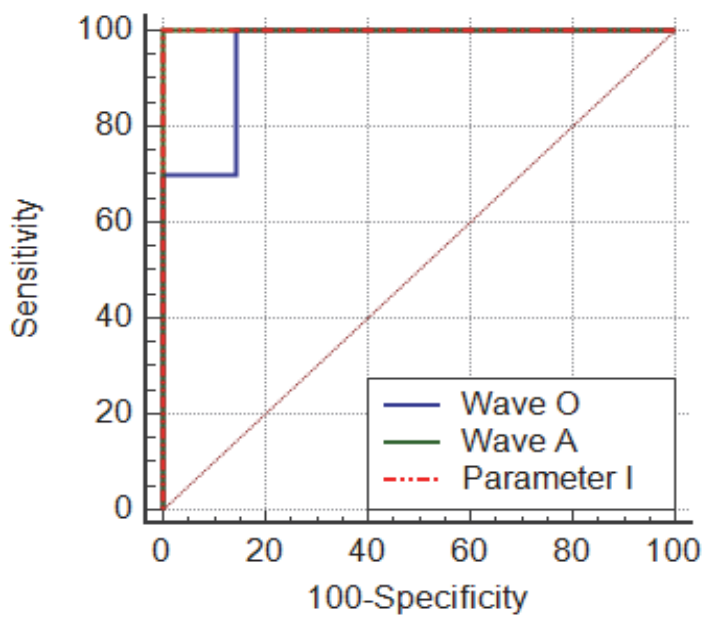

Fig.5: ROC curves for O- wave amplitude (AUC $=0.96$, $\mathrm{p}<0.0001)$, A- wave amplitude $(\mathrm{AUC}=1, \mathrm{p}<0.0001)$, and the diagnosis parameter "I" (AUC=1, $\mathrm{p}<0.0001)$.

As a support for the obtained results, we calculated hemodynamic parameters for the two groups of subjects. The main hemodynamic parameters are the heart rate (HR), the left ventricular ejection time (LVET), the stroke volume (SV) and the cardiac output (CO). We found that, there were highly significant differences between the two groups of subjects in LVET, $\mathrm{SV}$, and $\mathrm{CO}(\mathrm{p}<0.001)$, but there was no significant difference between the mean heart rate values for control subjects and patients with MI $(58 \pm 3 \mathrm{bpm}$ vs $58 \pm 7 \mathrm{bpm}$ ) (Table 4). Figure 6 shows that the SV and CO significantly decreased on patient with MI compared to the control subjects.

Table 4. The computed hemodynamic parameters for control subjects and patients with mitral insufficiency (mean \pm SD)

\begin{tabular}{|l|c|c|c|}
\hline \multicolumn{1}{|c|}{ ICG waves } & Control subjects & $\begin{array}{c}\text { Patients } \\
\text { with MI }\end{array}$ & t-values \\
\hline HR (bpm) & $58 \pm 3$ & $58 \pm 7$ & $\mathrm{n} / \mathrm{s}$ \\
\hline LVET (ms) & $270 \pm 110$ & $500 \pm 76$ & $7.50^{*}$ \\
\hline SV (ml) & $113.8 \pm 17.5$ & $70.7 \pm 12.2$ & $8.81^{*}$ \\
\hline CO $(1 / \mathrm{min})$ & $6.6 \pm 0.8$ & $4.1 \pm 1.1$ & $8.07^{*}$ \\
\hline
\end{tabular}

Note: HR: heart rate; LVET: left ventricle ejection time; SV: stroke volume; CO: cardiac output; * $<<0.001$ : the differences are highly significant. $\mathrm{n} / \mathrm{s}$ : not significant. 

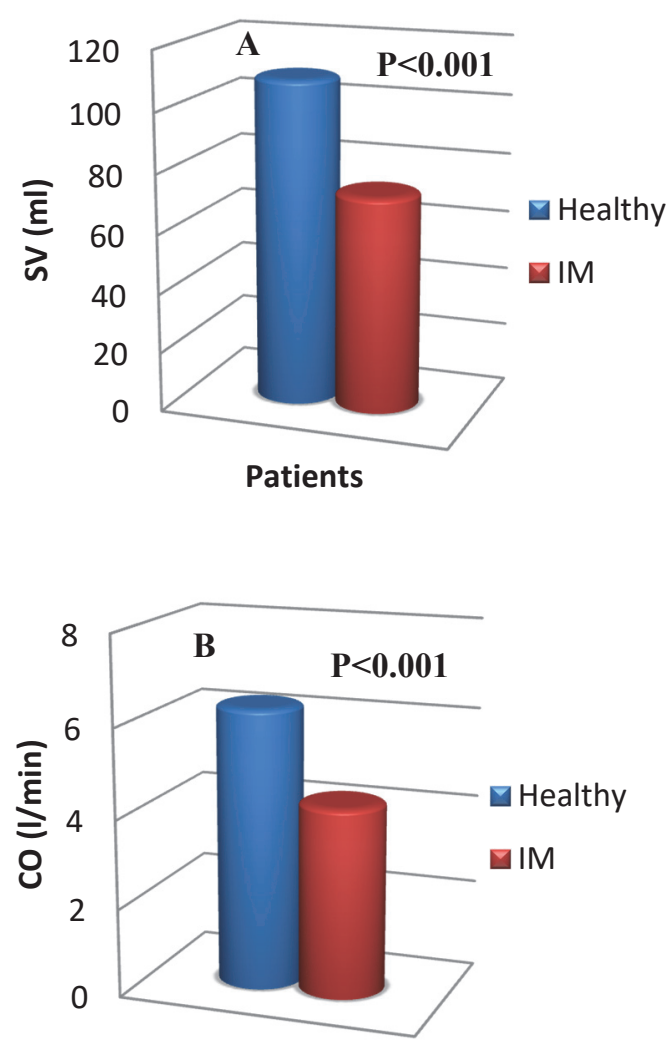

Patients

Fig.4: Difference between patients with mitral insufficiency (red) and control subjects (blue): (A) Histogram of stroke volume, (B) Histogram of cardiac output.

\section{Discussion}

The purpose of our study is to investigate the usefulness of the abnormalities of impedance cardiogram tracing in the diagnosis of mitral insufficiency disease (MI). The abnormalities of ICG waveforms were reproducible for each patient with MI. To facilitate the diagnosis of patients with MI, we proposed to discuss the amplitude of the A-waves and $\mathrm{O}$-waves, and to calculate a characteristic parameter "I". As described above, the A-wave is associated with the atrial contraction and the O-wave is associated with the opening of the mitral valve. The parameter "I" was obtained from the difference between the $\mathrm{O}$ and $\mathrm{A}$ wave amplitudes (I= O-A) of the ICG tracings. Therefore, "I" is affected by the systolic and diastolic parts of the ICG tracing. The results of this study demonstrate that the $\mathrm{O}$ - and A- waves are marked as significant parameters in the distinction of the mitral insufficiency disease. Thus, "I" is considered as an efficient tool that can be used to diagnose patients with MI (the diagnosis parameter "I" had sensitivity and specificity of $100 \%)$.

In order to evaluate the obtained results, we compared the main hemodynamic parameters (SV, CO, and LVET) for the two groups of patients. We found that the SV and $\mathrm{CO}$ significantly decreased in patients with MI compared to the control subjects. In fact, previous studies have shown that the SV and the CO decrease in patients with MI; these results were correlated with catheterization [29, 30]. Hence, the analysis of hemodynamic parameters, especially the SV and the $\mathrm{CO}$, has been found useful to diagnose the mitral insufficiency disease.

In order to diagnose pathologies, we suggest an automatical, simple, non-invasive, cheap and useful technique. The ICG technique has these characteristics, and it is selected to evaluate the performance of our study. Generally, the mitral insufficiency disease is diagnosed with Doppler echocardiography, which is expensive and requires expertise. Therefore, we used the impedance cardiography technique in order to facilitate the diagnosis. The results of the present study demonstrate that the ICG, especially the derived parameter "I", is considered as a simple and noninvasive tool for diagnosing the mitral insufficiency disease.

The main limitation of our study was the artifacts that can affect the shape of the ICG signal and can, therefore, affect the detection of the characteristic waves $\mathrm{O}$ and $\mathrm{A}$. The motion and the respiration noises are the most discriminant kinds of artifacts in the ICG signal. Thus, an ICG signal denoising step is necessary to ensure better results for this present study. ICG signal denoising details have been published previously [42].

In the future research, we will investigate and try to determine a specific parameter to evaluate the severity of the MI diseases. In addition, a larger number of patient are needed in order to further quantify and recommend our method.

\section{References}

1. R.P. Patterson. Impedance cardiography: What is the source of the signal? International Conference on Electrical Bioimpedance. Journal of Physics: Conference Series 224(2010)012118.

http://dx.doi.org/10.1088/1742-6596/224/1/012118

2. Donald P. Bernstein. Impedance cardiography: Pulsatile blood flow and the biophysical and electrodynamic basis for the stroke volume equations. J Electr. Bioimp. 2010; 1: 2-17.

3. P.H.H. Woltjer, H. J. Bogaard and P. M. J. M. de Vries. The technique of impedance cardiography. European Heart Journal. 1997; 18: 1396-1403.

http://dx.doi.org/10.1093/oxfordjournals.eurheartj.a015464

4. G. Cybulski, E. Michalak, E. Koluk, A. Pietkowska, W. Niewiadomski. Stroke volume and systolic time intervals: beat-to-beat comparison between echocardiography and ambulatory impedance cardiography in supine and tilted positions. Medical \& Biological Engineering \& Computing. 2004; 42: 707-711. http://dx.doi.org/10.1007/BF02347554

5. Maureen A.J.M. van Eijnatten, Michael J. van Rijssel, Rob J.A. Peters, Rudolf M. Verdaasdonk, and Jan H. Meijer. Comparison of cardiac time intervals between echocardiography and impedance cardiography at various heart rates. Journal of Electrical Bioimpedance. 2014; 5: 2-8. http://dx.doi.org/10.5617/jeb.690 
6. Andra Faini, Stefano Omboni, Marius Tifrea, Serban Bubenek, Ovidiu Lazar, and Gianfranco Parati. Cardiac index assessment: Validation of a new non-invasive very low current thoracic bioimpedance device by thermodilution. Blood Pressure. 2014; 23(2): 102-108. http://dx.doi.org/10.3109/08037051.2013.817121

7. A. Scherhag, J.J. Kaden, E. Kentschke, T., Sueselbeck, and M. Borggrefe. Comparison of Impedance Cardiography and Thermodilution-Derived Measurements of Stroke Volume and Cardiac Output at Rest and During Exercise Testing. Cardiovascular Drugs and Therapy. 2005; 19: 141-147. http://dx.doi.org/10.1007/s10557-005-1048-0

8. Milo Engoren and Daniel Barbee. Comparison of cardiac output determined by bioimpedance, thermodilution, and the Fick method. American Journal of Critical Care. 2005; 14: 40-45.

9. F. Khraim, R. Pike, J. Williams. Using non invasive impedance cardiography to assess cardiac hemodynamic measures of persons with heart failure. Canadian Journal of Cardiology. 2014; 30(10), S371. http://dx.doi.org/10.1016/j.cjca.2014.07.708

10. Milton Packer, William T. Abraham, Mandeep R. Mehra. Utility of Impedance Cardiography for the Identification of Short-Term Risk of Clinical Decompensation in Stable Patients with Chronic Heart Failure. Journal of the American College of Cardiology. 2006; 47(11): 2245-2252. http://dx.doi.org/10.1016/j.jacc.2005.12.071

11. Shun-Juan Chen, Zhu Gong, and Qiang-Lin Duan. Evaluation of heart function with impedance cardiography in acute myocardial infarction patients. Int. J. Clin. Exp. Med. 2014; 7(3): 719-727.

12. A. Zielińska, H. Dudek, G. Cybulski. Application of Impedance Cardiography for Haemodynamic Monitoring in Patients with Ischaemic Stroke. XIII Mediterranean Conference on Medical and Biological Engineering and Computing. 2014; 41: 993-995. http://dx.doi.org/10.1007/978-3-319-00846-2_246

13. Jan H. Meijer, Eskeline Elbertse, Sanne Boesveldt, Henk W. Berendse, and Rudolph M. Verdaasdonk. Using the Initial Systolic Time Interval to assess cardiac autonomic nervous function in Parkinson's disease. Journal of Electrical Bioimpedance. 2011; 2: 98-101. http://dx.doi.org/10.5617/jeb.216

14. Tomohiko Nakamura, Masaaki Hirayama, Takashi Haraa, Yasuaki Mizutani, Junichiro Suzuki, Hirohisa Watanabe, Gen Sobue. Role of cardiac sympathetic nerves in preventing orthostatic hypotension in Parkinson's disease. Parkinsonism \& Related Disorders. 2014; 20(4): 409-414. http://dx.doi.org/10.1016/j.parkreldis.2014.01.003

15. J. Burlingame, P. Ohana, M. Aaronoff, and T. Seto. Noninvasive cardiac monitoring in pregnancy: impedance cardiography versus echocardiography. Journal of Perinatology. 2013; 33(9): 675-680. http://dx.doi.org/10.1038/jp.2013.35

16. Manfred G. Moertl, Dietmar Schlembach, Ilona Papousek, Helmut Hinghofer-Szalkay, Elisabeth M Weiss, Uwe Lang and Helmut K Lackner. Hemodynamic evaluation in pregnancy: limitations of impedance cardiography. Physiological Measurement. 2012; 33: 1015-1026. http://dx.doi.org/10.1088/0967-3334/33/6/1015
17. Adriano R. Tonelli, Hassan Alnuaimat, Ning Li, Robin Carrie, Kamal K. Mubarak.Value of Impedance Cardiography in Patients Studied for Pulmonary Hypertension. Lung. 2011; 189: 369-375. http://dx.doi.org/10.1007/s00408-011-9299-y

18. Paweł Krzesiński,Grzegorz Gerard Gielerak, and Jarosław Józef Kowal. A "patient-tailored" treatment of hypertension with use of impedance cardiography: A randomized, prospective and controlled trial. Medical Science Monitor. 2013; 19: 242-250. http://dx.doi.org/10.12659/MSM.883870

19. Liisa Kokkonen, Silja Majahalme, Tiit Kööbi et al. Atrial fibrillation in elderly patients after cardiac surgery: Postoperative hemodynamics and low postoperative serum triiodothyronine. Journal of Cardiothoracic and Vascular Anesthesia. 2005; 19(2): 182-187. http://dx.doi.org/10.1053/j.jvca.2005.01.028

20. Annemieke Smorenberga, Erik J. Lusta, Albertus Beishuizena, Jan H. Meijer, Ruud M. Verdaasdonk, and A.B. Johan Groeneveld. Systolic time intervals vs invasive predictors of fluid responsiveness after coronary artery bypass surgery. European Journal of Cardio-Thoracic Surgery. 2013; 44: 891-897. http://dx.doi.org/10.1093/ejcts/ezt108

21. Julie L. Wynne, Leo O. Ovadje, Chaltsy M. Akridge et al. Impedance Cardiography: A Potential Monitor for Hemodialysis. Journal of Surgical Research. 2006; 133(1): 55-60. http://dx.doi.org/10.1016/j.jss.2006.03.004

22. Laura M. Roa, David Naranjo, Javier Reina-Tosina, Alfonso Lara, José A. Milán, Miguel A. Estudillo, J. Sergio Oliva. Applications of Bioimpedance to End Stage Renal Disease (ESRD). Modelling and Control of Dialysis Systems. Studies in Computational Intelligence. 2013; 404: 689-769.

23. Giovanni B. Pedrazzini, Francesco F. Faletra, Giuseppe Vassalli, Stefanos Demertzis, Tiziano Moccetti. Mitral Regurgitation. Swiss. Med. Wkly. 2010; 140(3-4): 36-43.

24. Michele De Bonis, Francesco Maisano, Giovanni La Canna and Ottavio Alfieri. Treatment and management of mitral regurgitation. Nature Reviews/ Cardiology. 2012; 9: 133146. http://dx.doi.org/10.1038/nrcardio.2011.169

25. Christian Bruch, Jörg Stypmann, Rainer Gradaus, Günter Breithardt, and Thomas Wichter. Usefulness of Tissue Doppler Imaging for Estimation of Filling Pressures in Patients With Primary or Secondary Pure Mitral Regurgitation. Am. J. Cardiol. 2004; 93: 324-328. http://dx.doi.org/10.1016/j.amjcard.2003.10.012

26. Abhvinav Diwan, Marti McCulloch, RDCS; Gerald M. Lawrie, Michael J. Reardon, Sherif F. Nagueh. Doppler Estimation of Left Ventricular Filling Pressures in Patients with Mitral Valve Disease. Journal of the American Heart Association, Circulation. 2005; 111: 3281-3289. http://dx.doi.org/10.1161/circulationaha.104.508812

27. Giovanna Branzi, Gabriella Malfatto, Alessandra Villani, Francesca Ciambellotti, Miriam Revera, Alessia Giglio, Francesco Della Rosa, Mario Facchini and Gianfranco Parati. Acute effects of levosimendan on mitral regurgitation and diastolic function in patients with advanced chronic heart failure. Journal of Cardiovascular Medicine. 2010; 11(9): 662-668. http://dx.doi.org/10.2459/JCM.0b013e32833832f6 
28. Jeffrey R. Bender. Heart Valve Disease. Yale University School of Medicine Heart Book, Chapter13, 167-175, 1992.

29. James N Karnegis, Jeanne Heinz, William G Kubicek. Mitral regurgitation and characteristic changes in impedance cardiogram. Br. Heart J. 1981; 45: 542-48. http://dx.doi.org/10.1136/hrt.45.5.542

30. R. M. Schieken, M. R. Patel, H. L. Falsetti, R. M. Lauer. Effect of mitral valvular regurgitation on transthoracic impedance cardiogram. Br. Heart J. 1981; 45: 166-72. http://dx.doi.org/10.1136/hrt.45.2.166

31. I. Viscor, P. Jurak, V. Vondra, J. Halamek, P. Leinveber. Stroke Volume during Mueller Maneuver Measured by Impedance Cardiography in Patients with Mitral Regurgitation. Computers in Cardiology. 2009; 36: 749-751.

32. R. Ben Salah, A. Marrakchi, and N. Ellouze. Cardiac diseases quantification of by temporal and cepstral analysis of plethysmographic signal. Journal of Islamic Academy of Sciences. 1989; 2(3): 204-211.

33. Cybulski Gerard. Ambulatory Impedance Cardiography. Springer, 2011.

34. D.L. Lozano, G. Norman, D. Knox, B.L. Wood, B.D. Miller, C.F. Emery, G.G. Berntson. Where to B in dZ/dt. Psychophysiology. 2007; 44(1): 113-119. http://dx.doi.org/10.1111/j.1469-8986.2006.00468.x

35. A. Sherwood, M.T. Allen, J. Fahrenberg, R.M. Kelsey, W.R. Lovallo, L.J.P.v an Doornen. Methodological guidelines for impedance cardiography. Psychophysiology. 1990; 27: 1-23. http://dx.doi.org/10.1111/j.1469-8986.1990.tb02171.x
36. A.P. DeMarzo, R.M. Lang. A New Algorithm for Improved Detection of Aortic Valve Opening by Impedance Cardiography. Computers in Cardiology. 1996; 0276-6547.

37. D. S. Goldstein, R. O. Cannon, R. Zimlichman, and H. R. Keiser. Clinical evaluation of impedance cardiography. Clinical Physiology. 1986; 6: 235-251. http://dx.doi.org/10.1111/j.1475-097X.1986.tb00622.x

38. W. Kubicek, A. From, R. Patterson, D. Witsoe, A. Castaneda, R. Lillehei, and R. Ersek. Impedance cardiography as a noninvasive means to monitor cardiac function. American Association for Advancement of Medical Instrumentation. 1970; 4: 79-84.

39. Kazuo Takada, Takao Fujinami, Katsuji Senda, Koichi Nakayama, Sagami Nakano. Clinical study of "'A waves" (atrial waves) in impedance cardiograms. American Heart Journal. 1979; 94: 710-717. http://dx.doi.org/10.1016/S00028703(77)80211-1

40. Z. Lababidi, D. A. Ehmke, R.E. Durnin, P.E. Leaverton and R.M. Lauer. The First Derivative Thoracic Impedance Cardiogram. Circulation. 1970; 41: 651-658. http://dx.doi.org/10.1161/01.CIR.41.4.651

41. Jean Bour, John Kellett. Impedance cardiography - a rapid and cost-effective screening tool for cardiac disease. European Journal of Internal Medicine. 2008; 19(6), 399405. http://dx.doi.org/10.1016/j.ejim.2007.07.007

42. S. Chabchoub, S. Mansouri, R.B Salah. Impedance cardiography signal denoising using discrete wavelet transform. Australas. Phys. Eng. Sci. Med. 2016; 39(3): 655663. http://dx.doi.org/10.1007/s13246-016-0460-z 